\title{
Effects of Written Emotional Expression: The Role of Positive Expectancies
}

\author{
Thomas A. Langens \\ University of Wuppertal
}

\author{
Julia Schüler \\ University of Zurich
}

\begin{abstract}
Objective: Writing in an emotional way about stressful or traumatic experiences has beneficial effects on emotional well-being and physical health. Yet the mechanisms that underlie these effects still need to be explored. Integrating research on the effects of positive expectancies, the authors suggest that positive effects of written emotional expression may, in part, depend on expectancies induced by writing about emotional experiences. Design: Two studies were conducted to test this hypothesis. In both studies, participants wrote about either an upsetting event or trivial issues. After the writing period, participants rated their expectancies that the writing intervention would improve (or impair) their emotional wellbeing over time. Main Outcome Measures: Study 1 assessed the emotional impact of an upsetting event, whereas Study 2 assessed subjective reports of physical symptoms. In both studies, outcome variables were collected both before and 6 weeks after the writing intervention. Results: The results showed that (a) writing about upsetting experiences induced higher positive expectancies than writing about trivial issues and (b) expectancies associated with written emotional expression were related to a reduction in the emotional impact of an upsetting event (Study 1) and to a reduction in physical symptoms (Study 2). Conclusions: There may be 2 alternative ways to render written emotional expression effective in reducing negative emotions: (a) by rendering an emotional experience more meaningful and (b) by inducing positive affect regulation expectancies.
\end{abstract}

Keywords: emotional expression, response expectancies, emotion regulation, coping

Having to deal with negative emotions such as anxiety, sadness, or anger seems to be an inevitable characteristic of human life. It is not surprising, then, that most people have developed or adopted affect regulation strategies that they can use to reduce negative emotions (Parkinson, Totterdell, Briner, \& Reynolds, 1996). ${ }^{1}$ Affect regulation strategies do not work like medical drugs: Whereas an analgesic may have very similar effects for most people (Amanzio, Pollo, Maggi, \& Benedetti, 2001), common affect regulation strategies, such as "talking it all over with a friend," "jogging through the park," or "having a good time at the movies" (cf. Thayer, Newman, \& McClain, 1994), do the trick for some people but may not work at all for others. Thus, there must be other psychological variables that determine the effectiveness of affect regulation strategies. In the following study, we first review research on emotional expression, a common affect regulation strategy. Then we argue that positive expectancies may be a key ingredient in many diverse affect regulation strategies. Combining these two lines of research, we propose that positive expectancies may play an important role in emotional expression.

Thomas A. Langens, Department of Psychology, University of Wuppertal, Wuppertal, Germany; Julia Schüler, Department of Psychology, University of Zurich, Zurich, Switzerland.

We thank Dorothea Krämer and Stephanie Eilers for their help in data collection.

Correspondence concerning this article should be addressed to Thomas A. Langens, Department of Psychology, University of Wuppertal, Gaussstrasse 20, 42097, Wuppertal, Germany. E-mail: langens@uni-wuppertal.de

\section{Emotional Expression and Affect Regulation}

A program of research spearheaded by Pennebaker (1997) found that writing about upsetting experiences in an emotional way (which we also call written emotional expression) has beneficial effects on emotional well-being and physical health. In their seminal study, Pennebaker and Beall (1986) had participants write about the most traumatic experience of their life for $15 \mathrm{~min}$ a day over the course of 4 days and found that students who elaborated traumatic experiences both cognitively and emotionally subsequently reduced their number of health center visits. A metaanalysis of writing studies conducted subsequently (Smyth, 1998; see also Lepore \& Smyth, 2002) demonstrated that written emotional expression also has beneficial effects on blood markers of immune functions, general functioning, and subjective emotional well-being.

A key ingredient of written emotional expression seems to be the deliberate confrontation of upsetting events (Weinberger \& Eig, 1999). According to Pennebaker and Seagal (1999), confrontation by written emotional expression can help to integrate stressful experiences into a coherent narrative, which may render the traumatic experience more meaningful. Once a person has devel-

\footnotetext{
${ }^{1}$ In the present article, we use the concept of affect regulation rather than coping because affect regulation is the broader term. Whereas coping typically refers to dealing with events that are taxing or exceed a person's resources (cf. Lazarus \& Folkman, 1984), affect regulation can occur in the absence of a challenging event (e.g., Parkinson et al., 1996). However, most researchers have noticed a great overlap between affect regulation strategies and coping strategies (Parkinson \& Totterdell, 1999).
} 
oped a new understanding of the stressful experience, the event can "be summarized, stored, and forgotten more efficiently" (Pennebaker \& Seagal, 1999, p. 1248). In support of this hypothesis, Pennebaker, Mayne, and Francis (1997; see also Klein \& Boals, 2001) found that participants who increased their usage of insight words during the course of a 3-day writing period showed the largest decreases in number of health center visits. Neither participants who used many insight words at the beginning of the intervention (i.e., who had a fixed conception of the stressful event) nor participants who did not use insight words at all (i.e., who did not find any meaning in the event) benefited as much from the writing intervention.

However, there are also studies that suggest that emotional expression can have no or adverse effects on emotional well-being (e.g., Earnhardt, Martz, Ballard, \& Curtin, 2002; Gallagher \& MacLachlan, 2002). Honos-Webb, Harrick, Stiles, and Park (2000) found that writing about upsetting experiences might have retraumatized some of their participants. More generally, Wortman and Silver $(1989,2001)$ maintained that "working through" the emotions associated with a loss is, for most people, neither a necessary nor a sufficient condition for successful coping. Overall, then, there is mixed evidence concerning the effectiveness of emotional expression. In the following, we suggest that researchers may explain inconsistencies by examining the role of expectancies in affect regulation.

\section{Expectancies and Affect Regulation}

Research accumulated over the past 30 years has yielded conclusive evidence that expectancies have a profound impact on subjective mood and physical well-being. For example, dispositional optimism- defined as the generalized expectancy that positive things will happen in the future-is related to an absence of negative mood and to good health (Scheier \& Carver, 2003). Overall, individuals high in dispositional optimism report more positive and less negative mood than pessimistic individuals (Scheier, Carver, \& Bridges, 2001). Recent studies have found that optimism seems to decrease the detrimental effects of daily hassles, as indexed by negative mood and immune changes (Segerstrom, Taylor, Kemeny, \& Fahey, 1998), and that optimism was associated with a faster rate of physical recovery during a period of hospitalization after coronary artery bypass surgery (Scheier et al., 2003). In sum, optimism seems to have beneficial effects on both subjective emotional well-being and physical health.

Expectancies also seem to be an active ingredient in many specific affect regulation strategies. A series of studies has found that mood regulation expectancies are related to changes in depressive mood and physical symptoms. In particular, people who have high expectancies that they will be able to regulate negative emotions typically report less depressive mood and fewer physical symptoms subsequently (Catanzaro \& Greenwood, 1994; Catanzaro, Wasch, Kirsch, \& Mearns, 2000; Kirsch, Mearns, \& Catanzaro, 1990). More important, these studies also suggest that the effect of active coping strategies (e.g., problem solving or seeking instrumental support) also depends on mood regulation expectancies. Typically, active coping is related to reductions in negative mood over time (Folkman \& Lazarus, 1988). However, when mood regulation expectancies are statistically held constant, then active coping strategies are related to increases in depressive mood
(Catanzaro \& Greenwood, 1994; Catanzaro, Horaney, \& Creasey, 1995; Kirsch et al., 1990). Thus, active coping strategies are not effective in themselves. They seem to be effective only to the extent that people have high expectations that they will be able to achieve a better mood state by using these strategies.

In sum, both generalized positive expectancies (e.g., optimism) and positive mood regulation expectancies predict emotional wellbeing and an absence of physical symptoms. These findings can easily be integrated into Kirsch's $(1985,1990)$ concept of response expectancies, which he defined as expectancies concerning the occurrence of nonvolitional responses. According to this theoretical framework, response expectancies tend to be self-fulfilling. Thus, the expectancy that negative emotions (a nonvolitional response) will be reduced-either because of an action (e.g., writing a diary) or because of a specific situation (e.g., a friend comes over for dinner) - tends to reduce negative emotions. Following this lead, Catanzaro et al. (2000) came to the conclusion that "when an individual believes that some volitional behavior will result in a more positive mood, performing that behavior will lead to a better mood-even if the behavior itself has no systematic effect on mood for people in general" (p. 760).

\section{The Present Research}

The research reviewed so far seems to suggest that one active ingredient in written emotional expression may be positive expectancies associated with expressive writing. Talking or writing about stressful experiences is a common strategy to reduce negative emotions, so it seems quite plausible that most people have positive expectancies that doing so will improve their mood. Note that we are not suggesting that the effects of written emotional expression can be fully accounted for by expectancies associated with emotional writing. We are well aware of the wealth of studies that show that developing a new understanding of stressful experiences by written emotional expression is a sufficient condition for positive effects to occur (Pennebaker, 1997). However, we do suggest that positive expectancies may play an active role in written emotional expression. In particular, we suggest that writing about upsetting events induces high positive affect regulation expectancies and that, in turn, these expectancies may lead to improvements in emotional well-being and physical health.

We conducted two studies to test this hypothesis. In both studies, participants wrote either about an upsetting event or about trivial issues. After the writing period, participants rated their expectancies that the writing intervention would improve (or impair) their emotional well-being over time. In Study 1, participants filled in a measure of the emotional impact of an upsetting event both before and 6 weeks after the writing intervention. In Study 2, participants filled in a checklist of physical symptoms both before and 6 weeks after the intervention. Impact of stressful events and reports of physical symptoms were selected as outcome measures in the present research because similar measures have been used in studies investigating the effects of emotional expression (impact of stressful events: Lepore, Ragan, \& Jones, 2000; ratings of physical symptoms: Greenberg, Wortman, \& Stone, 1996) as well as in studies examining the effects of positive expectancies (impact of stressful events: Segerstrom et al., 1998; physical symptoms: Catanzaro et al., 2000; Scheier et al., 2003). We hypothesized that expectancies would be more positive for participants writing about 
upsetting (rather than trivial) experiences. We also hypothesized that expectancies would be related to decreases in the emotional impact of upsetting events and to decreases in physical symptoms.

\section{Study 1}

Study 1 tested whether expectancies associated with written emotional expression are related to changes in the emotional impact of an upsetting event. At the beginning of the study, participants brought to their mind an upsetting event and rated the emotional impact of this event. Then, one group of participants wrote about this event in an emotional way (experimental condition), and the other group wrote about trivial issues (control condition). After the writing task, participants in both conditions rated expectancies associated with the writing task. We decided to measure expectancies after (rather than prior to) the writing intervention because there is evidence that expectancies rooted in actual experience are a stronger predictor of subsequent responses than expectancies based on nonexperiential sources of information, such as vicarious experiences or verbal persuasion (Bandura, 1998; Kirsch, 1990). Six weeks later, all participants rated the emotional impact of their event a second time.

\section{Method}

Participants and procedure. Data were collected in two phases. At the beginning of the study (Time 1 [T1]), 62 students ( 49 women and 13 men; age, $M=28.2$ years, $S D=9.6$ ) were recruited for a study on "writing and psychology." Participants were tested individually in a psychology lab. The experimenter asked the participants to think about an upsetting event that was still on their mind, to write down eight words they associated with the event, and to fill in the Impact of Events Scale (IES; Horowitz, Wilner, \& Alvarez, 1979), which was also used by Lepore et al. (2000), with respect to this upsetting event. ${ }^{2}$ Then participants were assigned randomly to one of two conditions: an experimental condition, in which participants were asked to write about their upsetting event $(n=32)$, or a control condition, in which they were asked to write about trivial topics $(n=30)$. Students were allowed to write their essay at home but were reminded to start writing the essay the same night. In both conditions, participants were informed that they were free to drop out of the study at any time. Six weeks after participants finished writing their essay (T2), they were again asked to fill in the IES with regard to the upsetting event they mentioned in the first session. Overall, 6 participants (4 participants in the experimental condition and 2 participants in the control condition) dropped out of the study. Thus, complete data sets were obtained for 56 participants (experimental condition, $n=28$; control condition, $n=28$ ).

IES. The IES assesses the emotional impact of an event by measuring both intrusions of thoughts and images related to a stressful event (seven items; e.g., "I thought about it when I didn't mean to") and cognitive avoidance of the event (eight items; e.g., "I wished to banish it from my store of memories"). Participants had to rate each item on a 4-point-scale with endpoints labeled not at all ( 0 ) and often (3). Items were combined to give a single IES score (possible range $=0$ to $3 ; M=1.33, S D=0.53$, for $\mathrm{T} 1 ; M=1.13, S D=0.56$, for T2), which had good internal consistency at both $\mathrm{T} 1(\alpha=.81)$ and $\mathrm{T} 2(\alpha=.82)$.

Writing intervention. In the experimental condition, participants were asked to write about the upsetting emotional experience they had thought of in the first session on 3 consecutive days for $20 \mathrm{~min}$ each day. They were assured that their essays would be anonymous and that they would not receive feedback on them. Following Pennebaker's (e.g., Pennebaker, 1997) instructions, participants were told:

I would like you to write about the upsetting event you thought about today in the psych lab. In your writing, I'd like you to really let go and explore your deepest emotions and thoughts. You might tie your topic to your relationships with others, including parents, lovers, friends, or relatives; to your past, your present, or your future; or to who you have been, you would like to be, or who you are now.

Participants wrote about a wide range of stressful events, including low self-esteem, academic failure, divorce of parents, arguments with family or friends, problems in a romantic relationship, termination of a romantic relationship, and facing a chronic or potentially fatal disease.

Participants in the control condition were asked to write about an assigned topic on each of the 3 days and to spend $20 \mathrm{~min}$ on each essay. In keeping with Pennebaker and Beall (1986), the topics included trivial issues such as "my way to school" and "my apartment." The experimenter emphasized that participants should refrain from discussing emotions or feelings in their essays.

Expectancies. On the last day of the writing intervention, participants rated the expectancies associated with the writing intervention. As can be seen in Table 1, items assessed positive expectancies that the writing intervention would have beneficial effects and negative expectancies that the writing intervention would impair their emotional well-being. Another two items asked for the amount of understanding gained as a consequence of the writing intervention. All items had to be rated on a 5-point scale with endpoints labeled strongly disagree (1) and strongly agree (5). Internal consistency was sufficient for the three scales (positive expectancy, $\alpha=$ .86; negative expectancy, $\alpha=.81$; understanding, $\alpha=.76$ ). Because positive and negative expectancies were highly correlated $(r=-.61, p<$ .001 ), we created a score of resultant positive expectancies by reversing items assessing negative expectancies and combining items assessing positive expectancies to give a single scale $(\alpha=.92)$.

\section{Results}

Preliminary analyses. Exploratory analyses showed that neither gender nor age of participants had a significant impact on the results reported below.

Expectancies. Resultant positive expectancies associated with the writing intervention were significantly higher in the experimental condition $(M=3.87, S D=0.62)$ than in the control condition $(M=3.14, S D=0.65), t(54)=4.30, p<.001$. Further analyses showed that positive expectancies were higher in the experimental condition $(M=3.74, S D=0.73)$ than in the control condition $(M=2.63, S D=0.58), t(54)=6.28, p<.001$. Negative expectancies tended to be lower in the experimental condition $(M=2.00, S D=0.62)$ than in the control condition $(M=2.34, S D=0.86), t(54)=1.74, p=.09$. These data provide initial evidence that writing about upsetting experiences induced more positive expectancies than writing about trivial topics. Additional analyses revealed that the severity of the stressful event identified by participants - as indexed by the IES score at T1was unrelated to resultant positive expectancies in both conditions (experimental condition, $r=.06, p>.70$; control condition, $r=$ $.12, p>.50)$.

\footnotetext{
${ }^{2}$ There is no indication that writing down single words associated with a stressful event may have an effect comparable to writing coherent narratives over several days (Pennebaker \& Seagal, 1999).
} 
Table 1

The Expectancy Questionnaire Used in Studies 1 and 2 to Assess Expectancies Associated With the Writing Intervention

\begin{tabular}{ll}
\hline \multicolumn{1}{c}{ Item } & \multicolumn{1}{c}{ Subscale } \\
\hline It was helpful to write about the upsetting experience. & Positive \\
Writing about the upsetting experience was a pointless task. & Negative \\
Having written about the upsetting experience will help me to get along in everyday life. & Positive \\
Having written about the upsetting experience will be more harmful than beneficial. & Negative \\
I think I might write about upsetting experiences in the future without being asked to. & Positive \\
I do not think that writing about the upsetting experience will have any positive effects. & Negative \\
Writing about upsetting experiences will help me to see things in a positive light. & Positive \\
I would have gotten along much better if I hadn't written about upsetting experiences. & Negative \\
Having written about the upsetting experience will have positive effects in the long run. & Positive \\
I do not think that I will write about an upsetting experience ever again. & Negative \\
After having written about the experience, I understand things more clearly than before. & Understanding \\
Writing about the upsetting event did not increase my understanding of the event. & Understanding (reversed) \\
\hline
\end{tabular}

Note. Items assessed positive expectancies (Positive), negative expectancies (Negative), and the amount of understanding gained through writing (Understanding). In the control conditions of Studies 1 and 2, the term upsetting event was changed to everyday events. In the venting condition of Study 2 , it was changed to negative emotions.

Emotional impact. We analyzed participants' IES scores at T2 by using the following hierarchical regression approach. ${ }^{3}$ After controlling for IES scores at T1 (Step 1), we entered resultant positive expectancies and the experimental condition (dummy coded: expressive writing $=1$, control $=0$ ) into the regression equation (Step 2), followed by the multiplicative interaction of expectancies and the experimental condition (Step 3). To account for differences in expectancies between the two experimental conditions, we transformed resultant expectancies to $z$ scores in each condition. After we controlled for initial IES scores, neither expectancies nor the experimental condition predicted IES scores at T2. However, there was a statistical trend for the interaction of the experimental condition and expectancies to predict the emotional impact of the upsetting event at T2 $(b=-.19, S E=.10$, $\left.\Delta R^{2}=.028\right), t(51)=2.00, p=.051$. To probe this interaction, we calculated correlations between expectancies and emotional impact at T2 (controlling for emotional impact at T1) separately for the two experimental conditions. For the experimental condition, this correlation was highly significant (partial $r[p r]=-.50, p<$ $.01)$ and significantly stronger than for the control condition ( $p r=$ $.06, p>.90 ; z=2.16, p<.05)$. To further explore the nature of this interaction, we calculated predicted values of emotional impact at $\mathrm{T} 2$ using the regression weights from the final regression equation by following a procedure proposed by Cohen, Cohen, West, and Aiken (2003), in which values at one standard deviation above or below the mean of continuous predictor variables are entered in the regression equation. The results of this procedure are illustrated in Figure 1, which suggests that written emotional expression reduces the emotional impact of an event when people have positive expectancies that writing will have a beneficial effect. Conversely, Figure 1 also suggests that writing about upsetting experiences may increase the emotional impact of an upsetting event when people have predominantly negative expectancies.

\section{Discussion}

Study 1 found that people associate more positive expectancies with writing about an upsetting event than with writing about trivial issues. Note that most studies on written emotional expres- sion have compared interventions in which participants wrote about stressful or traumatic events with interventions in which participants wrote about trivial or everyday experiences. Although expectancies were not assessed in these studies, our results point to the possibility that expectancies were a confounding factor in a portion of studies on written emotional expression.

Furthermore, Study 1 also found that expectancies were related to changes in the emotional impact of an upsetting event for participants who wrote about the upsetting event but not for control participants who wrote about trivial topics. This result suggests that both positive expectancies and negative expectancies associated with expressive writing had a self-fulfilling effect in Study 1 . That is, participants who wrote about an upsetting event and were confident that writing would have beneficial effects rated the event as less severe 6 weeks after the writing intervention. However, writing about upsetting experiences seemed to increase the emotional impact of the event if people had severe doubts that writing could help.

Expectancies did not seem to have any effect for participants who wrote about trivial issues. Most probably, control participants did not see a compelling reason why writing about trivial issues might have any impact on their emotional well-being. In Study 2, we further explore this issue by including another condition that lacks the key ingredient of written emotional expression (i.e., confrontation) but that is commonly expected to be effective in regulating negative emotions. Also, Study 2 seeks to replicate the main results of Study 1 using a different outcome measure, namely, self-rated physical symptoms.

\section{Study 2}

As mentioned earlier, several authors have agreed that confrontation is a crucial factor for the effectiveness of written emotional expression (Pennebaker \& Seagal, 1999; Smyth, 1998; Weinberger \& Eig, 1999). However, the results of Study 1 suggest that some studies on written emotional expression might have confounded

${ }^{3}$ Following suggestions by Cohen et al. (2003), we centered continuous variables before subjecting them to hierarchical regression analyses. 


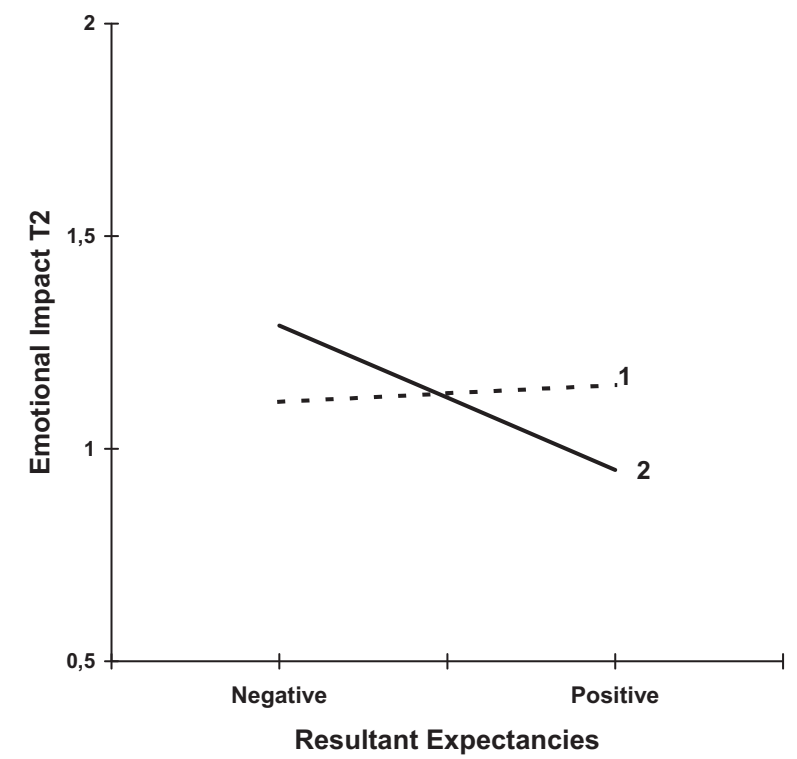

Figure 1. Emotional impact at Time 2 (T2) as a function of the writing intervention ( $1=$ control; 2 = expressive writing) and resultant positive expectancies (Study 1).

confrontation and positive expectancies. The experimental condition in a typical writing study (i.e., writing about stressful or traumatic events) involves confrontation and possibly aroused positive expectancies, whereas the typical control condition (writing about trivial issues) does not involve confrontation and (compared with expressive writing) does not arouse positive expectancies. To disentangle confrontation and expectancies, in Study 2 we introduce another writing intervention that does not involve confrontation but still arouses positive expectancies. In many cultures, people believe that venting negative emotions has positive effects on subsequent emotional well-being (Parkinson et al., 1996). According to Pennebaker and Seagal (1999), however, venting negative emotions will not improve emotional well-being or physical health because people cannot gain a new understanding of upsetting experiences without reflecting on the cognitive aspects of these experiences. Introducing a third condition in which participants write about the emotions associated with an upsetting event without describing the event itself makes it possible to further test the role of expectancies in written emotional expression. If a full (both cognitive and emotional) confrontation is a necessary condition for the beneficial effects of written emotional expression to occur, then participants who are just venting negative emotions should not report improved health even if they have high positive expectancies regarding this intervention. In contrast, if expectancies are a key factor in written emotional expression, then venting negative emotions should lead to improved well-being if people have high positive expectancies.

\section{Method}

Participants and overview of procedure. Data were collected in three phases. ${ }^{4}$ At the beginning of the semester (T1), 118 students (87 women and 31 men) were recruited for a study on "writing and psychology." Participants received a take-home booklet that contained questionnaires assessing physical symptoms. After participants had returned the booklet, they were assigned randomly to one of three conditions (T2): the standard "written emotional expression" group, asked to write about the cognitive and emotional aspects of stressful events (standard condition; $n=44$ ); the "venting" group, asked to write about emotions aroused by stressful events (venting condition; $n=30$ ); or a control group, asked to write about trivial topics (control condition; $n=44$ ). Students were allowed to write their essays at home but were reminded to start writing essays the same night. In all conditions, participants were informed that they were free to drop out of the study at any time. Whereas 16 participants of the standard condition (36\%) decided to discontinue their participation, only 2 participants in the venting condition (7\%) and 3 participants in the control condition (9\%) elected to drop out of the study, $\chi^{2}(2, N=118)=22.65, p<.01$. Six weeks after participants finished writing their essays (T3), they were again asked to fill in the physical symptoms checklist. Four participants ( 2 in the standard condition, 2 in the control condition) failed to pick up the follow-up questionnaire or could not be contacted. Thus, complete data sets were obtained for 93 participants (standard condition, $n=26$; venting condition, $n=28$; control condition, $n=39$ ).

Physical symptoms. Severity of physical symptoms was assessed with an abbreviated version of the Pennebaker Inventory of Limbic Languidness (Pennebaker \& Watson, 1991). For each of 16 physical symptoms (e.g., headaches, palpitations, muscle pains, dizziness, coughing), participants rated on a 4-point scale, with endpoints labeled not at all (1) and very much (4), how much they had experienced this symptom in the last week. Participants filled in the symptoms questionnaire twice, both at T1 and at T3. We derived a total score of physical symptoms by averaging responses for all 16 items ( $\mathrm{T} 1, \alpha=.76 ; \mathrm{T} 2, \alpha=.78$ ). On average, the severity of physical symptoms remained stable over the course of the study (T1, $M=$ $1.60, S D=0.44 ; \mathrm{T} 2, M=1.63, S D=0.50), t(92)=0.72, p>.40$.

Writing intervention. In the standard condition, participants were asked to write about one or more upsetting emotional experiences on 4 consecutive days for $20 \mathrm{~min}$ each day. Writing instructions were identical to those in Study 1. Participants in the venting condition were asked to write about the negative emotions that were aroused by one or more upsetting events on 4 consecutive days for 20 min each day. Participants were told,

In your writing, I want you to vent all the negative emotions that were aroused by a distressing experience and to describe your feelings as precisely and as detailed as possible. You might want to explore whether the experience aroused a single emotion or many different emotions. Or you may want to describe bodily reactions which were associated with your emotions. It is not important where your feelings came from. What is important is that you vent them as completely as possible. Please describe only your emotions. Do not describe the experiences which gave rise to your emotions.

After the completion of data collection, we checked whether participants adhered to the experimental instructions. In all but one of the protocols written by participants in the standard condition, at least one stressful experience was explicitly described. ${ }^{5}$ The majority of participants (23 of 26) wrote about one stressful event, and 2 participants wrote about two stressful events. Participants wrote about a wide range of stressful events, which were similar to the topics covered by experimental participants in Study 1, including low self-esteem; academic failure; death of a parent, a friend, or a sibling; arguments with family or friends; termination of a

\footnotetext{
${ }^{4}$ The data for Study 2 were collected as part of a larger project, and a portion of the data was examined in a study by Langens and Schüler (2005) to investigate a conceptually distinct set of issues.

${ }^{5}$ Removing from the data set the participant who did not explicitly describe a stressful event had no impact on the results, so he was retained in all data analyses.
} 
romantic relationship; involvement in an accident; and health problems. In addition, all of the participants in the standard condition wrote about the emotional aspects of stressful events. In contrast and in accord with the experimental instructions, none of the participants in the venting condition identified the actual experiences that gave rise to negative emotions; the participants only revealed and described negative emotional states. Thus, participants generally followed experimental instructions.

Participants in the control condition were asked to write about an assigned topic on each of 4 days and to spend 20 min on each essay. As in Study 1, the topics included trivial issues such as "my way to school" and "my apartment." The experimenter emphasized that participants should refrain from discussing emotions or feelings in their essays.

The three experimental conditions were coded by two dummy variables, experimental condition-standard (EC-standard) and experimental condition-venting (EC-venting). EC-standard was coded 1 if a participant took part in the standard condition and 0 otherwise. EC-venting was coded 1 if a participant took part in the venting condition and 0 otherwise (Hardy, 1993).

Expectancies. After participants had finished their last essay, they filled in the expectancy questionnaire that was also used in Study 1. Again, internal consistency was sufficient for the three subscales (positive expectancy, $\alpha=.87$; negative expectancy, $\alpha=.79$; understanding, $\alpha=.81$ ). Preliminary analyses showed that, in contrast to Study 1, gaining a new understanding of the experiences described in the essays was related to an increase in physical symptoms from T1 to T3 for both the standard condition $(p r=.29, p=.16)$ and the control condition $(p r=.34, p<$ .05 ). As in Study 2, we created a score of resultant positive expectancies by reversing items assessing negative expectancies and combining them with items assessing positive expectancies $(\alpha=.90)$.

\section{Results}

Attrition analyses and preliminary analyses. Participants in the standard condition who dropped out of the study did not differ from participants in the standard condition who completed the study in terms of severity of physical symptoms at $\mathrm{T} 1, t(42)=$ $0.50, p>.60$. Asked why they chose to quit their participation, most students responded that they "didn't feel like" writing about upsetting events. Thus, the generalizability of the results may be slightly restricted by participant attrition. Further preliminary analyses revealed that neither age nor gender of the participants had a significant impact on the results we report.

Expectancies. Analyses of variance of the three subscales of the expectancy questionnaire showed that the three conditions differed with respect to positive expectancies associated with the writing intervention, $F(2,90)=4.66, p<.05$. Planned contrasts confirmed that positive expectancies did not differ between the standard condition $(M=3.51, S D=0.87)$ and the venting condition $(M=3.27, S D=0.92), t(90)=0.94, p>.30$. However, these two conditions yielded significantly higher expectancies than the control condition $(M=2.88, S D=0.77), t(90)=2.93, p<$ .01 . There were no significant differences between the conditions for negative expectancies.

Physical symptoms. We analyzed physical symptoms at T3 by using the following hierarchical regression approach: Physical symptoms at $\mathrm{T} 1$ and understanding were entered as control variables in the first step of the hierarchical regression. Next, the two dummy variables coding the three experimental conditions (ECstandard and EC-venting) and resultant positive expectancies were entered in the regression equation. Finally, multiplicative interaction terms of EC-standard and EC-venting with expectancies were entered in the regression equation (Hardy, 1993; Kleinbaum, Kup- per, Muller, \& Nizam, 1998). With physical symptoms and understanding at T1 covaried out, there was a statistical trend for expectancies to be related to a reduction of physical symptoms $(b=-.21, S E=.12), t(87)=1.73, p=.09$. The experimental conditions did not account for a significant portion of the variance of physical symptoms at T3. However, the interaction of expectancies and the experimental conditions significantly predicted physical symptoms at T3 $\left(\Delta R^{2}=.036\right), F(2,85)=3.22, p<.05$. To explore the nature of this interaction, we calculated correlations between expectancies and physical symptoms at T3 (controlling for symptoms at $\mathrm{T} 1$ and understanding) for each of the three conditions. This correlation was nonsignificant for the control condition $(p r=.01)$ but significant for both the standard condition $(p r=-.55, p<.01)$ and the venting condition $(p r=-.42, p<$ .05 ). In addition, we calculated the predicted values of physical symptoms at $\mathrm{T} 3$, using the regression slopes from the final regression equation, for each of the three conditions, at values one standard deviation above or below the mean of expectancies. The resulting interaction pattern is illustrated in Figure 2 and suggests that having positive expectancies was related to fewer physical symptoms at $\mathrm{T} 3$ for both the standard and the venting conditions. In contrast, negative expectancies were associated with increased physical symptoms in these conditions. ${ }^{6}$

\section{Discussion}

Study 2 replicates the main results of Study 1, showing that (a) written emotional expression was associated with more positive expectancies than writing about trivial issues and (b) expectancies associated with written emotional expression were related to changes in physical symptoms. In addition, Study 2 demonstrates that expectancies also seem to determine the effect of venting negative emotions. This finding may be important because venting does not involve a full confrontation with stressful events, which, according to Pennebaker (1997; Pennebaker \& Seagal, 1999), is a necessary condition for the beneficial effects of written emotional expression to occur.

A problem with Study 2 is the high attrition rate in the experimental condition. After being instructed to write about upsetting experiences, approximately one third of the participants in the standard condition decided to quit their participation in the study. This figure is much higher than the attrition rate typically reported in writing studies (Pennebaker \& Seagal, 1999). We suspect that because we allowed participants to write at home and thus gave them time to contemplate their decision, some participants might have anticipated feeling badly immediately after the writing session (which is a typical response; see Smyth, 1998) and then decided to quit their participation. These results clearly show that some people may find it hard to articulate highly stressful events and, given a choice, may refrain from doing so.

${ }^{6}$ An additional intent-to-treat analysis was performed in which missing values of physical symptoms at T3 were imputed by physical symptoms at T1 (the last observation carried forward). Expectancies were imputed by the present sample's mean values. After we controlled for initial physical symptoms and understanding, this analysis still yielded a significant interaction of resultant expectancies and the experimental condition $\left(\Delta R^{2}=\right.$ $.029), F(2,110)=3.82, p<.05$. The pattern of this interaction was similar to the one illustrated in Figure 2. 


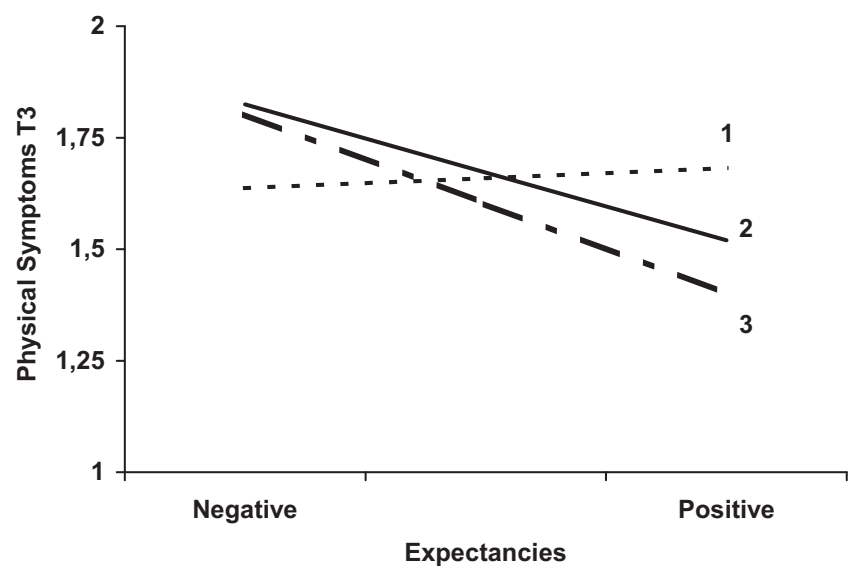

Figure 2. Physical symptoms at Time 3 (T3) as a function of the experimental condition $(1=$ control; $2=$ standard; $3=$ venting $)$ and resultant positive expectancies (Study 2).

\section{General Discussion}

The results of Studies 1 and 2 seem to indicate that expectancies may account for some of the effects of written emotional expression. First, both studies show that writing about an upsetting event induces positive expectancies that writing will have beneficial effects, whereas writing about trivial topics is associated with fewer positive expectancies. Second, the studies converge in demonstrating that expectancies associated with written emotional expression are related to changes in indicators of emotional and physical well-being. In both studies, expectancies associated with emotional writing had a self-fulfilling quality (cf. Kirsch, 1985, 1990). If participants believed that writing would have a positive effect, then writing was related to a reduction in the emotional impact of an upsetting event (Study 1) and to a reduction in physical symptoms (Study 2). Conversely, emotional writing seemed to impair emotional and physical well-being if participants had rather negative expectancies concerning the effects of emotional writing. The results of Study 2 also suggest that confrontation may not be a necessary condition for the positive effects of written emotional expression to occur, given that both the standard writing intervention and the emotional venting intervention had comparable effects. Most important, this effect depended on the quality of expectancies that were related to the writing intervention.

Our research converges with studies that have demonstrated that positive expectancies are related to a reduction in the impact of stressful events (e.g., Segerstrom et al., 1998) and to lower levels of physical symptoms (e.g., Catanzaro et al., 2000; Scheier et al., 2003). The link between expectancies and the impact of stressful events is considered to be either direct (e.g., Kirsch, 1985, 1990) or indirect (e.g., mediated by coping activities; Scheier et al., 2001). The link between expectancies and physical health seems to be mediated by emotional distress. Accumulating evidence suggests that emotional distress can have a direct impact on physical symptoms and on health status through biological pathways, notably through the suppression of immune function (Booth, 1998; Kiecolt-Glaser \& Glaser, 1995) and through autonomic activation (Uchino, Cacioppo, \& Kiecolt-Glaser, 1996). Most probably, pos- itive expectancies induced by emotional writing lead to a reduction in emotional distress, which then lowers autonomic activation and improves immune function, which, in turn, reduces the overall level of physical symptoms (Miller \& Schnoll, 2000)

It is important to note that positive expectancies were not related to changes in distress or physical symptoms for individuals who wrote about trivial topics. Thus, positive expectancies do not present a sufficient condition for a change of emotional well-being. The results of Studies 1 and 2 seem to suggest that for expressive writing to have an impact on emotional well-being, participants have to have some idea why an intervention should have a favorable effect. In contrast to writing about trivial topics, written emotional expression provides such a rationale: First and foremost, the belief in "talking things over" or "making up one's mind" is deeply ingrained in many Western cultures, most certainly since Breuer and Freud's (1895) concept of the "talking cure" was popularized. Second, the act of writing or talking about upsetting experiences shares many features with traditional purification rites. As van Gennep (1981) pointed out, purification rites are found in all known cultures and religions, both ancient and modern, preliterate and sophisticated, and they assume a wide variety of types and forms. The prevalence of purification rites may also provide a rationale for the effectiveness of written emotional expression. For example, writing about a stressful personal experience can be conceived of as some sort of "psychological hygiene" in which a person rids himself or herself of potentially harmful thoughts or images. Third, written emotional expression may induce highly effective expectancies because it establishes some of the features that are present in many healing ceremonies: engagement and negative affect. According to Frank (1974), the common element of traditional healing ceremonies is that they induce high expectancies by means of arousing negative emotions:

\footnotetext{
Healing ceremonies are highly charged emotionally. [A] shaman may act out a life-and-death struggle between his spirit and the evil spirit that has possessed the patient. The patient may vividly reenact past experiences or act out the struggles of the spirit forces within himself. The emotional excitement may be intensified by rhythmic music, chanting, and dancing. It frequently mounts to the point of exhausting the patient and not infrequently is enhanced by some strong physical shock. (Frank, 1974, p. 66)
}

Previous research has found that the immediate effect of writing about highly stressful experiences is an increase in negative emotions (Smyth, 1998). Our research clearly suggests that written emotional expression also induces positive expectancies that writing will improve emotional well-being in the long run. Judging from the analysis of traditional healing ceremonies by Frank (1974), this combination of effects may render written emotional expression especially effective.

Our results do not suggest that expectancies are the only active ingredient in written emotional expression. In fact, we do acknowledge that several studies found that gaining a new understanding of stressful experiences by writing can have a variety of beneficial effects (Klein \& Boals, 2001; Pennebaker et al., 1997; Pennebaker $\&$ Seagal, 1999). However, although confrontation may sometimes be a sufficient condition for successful coping, Study 2 seems to suggest that positive effects can occur in the absence of a fullblown cognitive and emotional confrontation with a stressful event. In sum, we suggest that there are two routes that may render 
written emotional expression highly effective in changing a person's emotional and physical well-being. Pennebaker et al. have presented convincing evidence that emotional writing is associated with better health and emotional well-being to the extent that it provides people with a new understanding of previously poorly understood traumatic or upsetting events. Our findings, however, seem to indicate that emotional expression may work to the extent that it induces high positive expectancies, which then lead to improvements in well-being.

In sum, our research yields encouraging results that show that expectancies play a key role in research on coping with stressful experiences through written emotional expression. By extending the scope and using different methodologies in future research, we may better be able to help people find more adaptive ways of coping with stress.

\section{References}

Amanzio, M., Pollo, A., Maggi, G., \& Benedetti, F. (2001). Response variability to analgesics: A role for non-specific activation of endogenous opioids. Pain, 90, 205-215.

Bandura, A. (1998). Self-efficacy (2nd ed.). New York: Guilford Press.

Booth, R. J. (1998). Stress and the immune system. In I. M. Roitt \& P. J. Delves (Eds.), Encyclopedia of immunology (2nd ed., pp 2220-2228). London: Academic Press.

Breuer, J., \& Freud, S. (1895). Studien über Hysterie [Studies on hysteria]. Leipzig, Germany: Deuticke.

Catanzaro, S. J., \& Greenwood, G. (1994). Expectancies for negative mood regulation, coping, and dysphoria among college students. Journal of Counseling Psychology, 41, 34-44.

Catanzaro, S. J., Horaney, F., \& Creasey, G. (1995). Hassles, coping, and depressive symptoms in an elderly community sample: The role of mood regulation expectancies. Journal of Counseling Psychology, 42, 259265.

Catanzaro, S. J., Wasch, H. H., Kirsch, I., \& Mearns, J. (2000). Coping related expectancies and dispositions as prospective predictors of coping responses and symptoms. Journal of Personality, 68, 757-788.

Cohen, P., Cohen, J., West, S. G., \& Aiken, L. S. (2003). Applied multiple regression/correlation analysis for the behavioral sciences (3rd ed.). Hillsdale, NJ: Erlbaum.

Earnhardt, J. L., Martz, D. M., Ballard, M. E., \& Curtin, L. (2002). A writing intervention for negative body-image: Pennebaker fails to surpass the placebo. Journal of College Student Psychotherapy, 17, 19-35.

Folkman, S., \& Lazarus, R. S. (1988). Coping as a mediator of emotion. Journal of Personality and Social Psychology, 54, 466-475.

Frank, J. D. (1974). Persuasion and healing. New York: Schocken Books.

Gallagher, P., \& MacLachlan, M. (2002). Evaluating a written emotional disclosure homework intervention for lower-limb amputees. Archives of Physical Medicine and Rehabilitation, 83, 1464-1466.

Greenberg, M. A., Wortman, C. B., \& Stone, A. A. (1996). Emotional expression and physical health: Revising traumatic memories or fostering self-regulation? Journal of Personality and Social Psychology, 71, $588-602$.

Hardy, M. A. (1993). Regression with dummy variables. Thousand Oaks, CA: Sage.

Honos-Webb, L., Harrick, E. A., Stiles, W. B., \& Park, C. L. (2000). Assimilation of traumatic experiences and physical-health outcomes: Cautions for the Pennebaker paradigm. Psychotherapy: Theory, Research, Practice and Training, 37, 307-314.

Horowitz, M., Wilner, N., \& Alvarez, W. (1979). Impact of Event Scale: A measure of subjective stress. Psychosomatic Medicine, 41, 209-218. Kiecolt-Glaser, J. K., \& Glaser, R. (1995). Psychoneuroimmunology and health consequences: Data and shared mechanisms. Psychosomatic Medicine, 57, 269-274.

Kirsch, I. (1985). Response expectancy as a determinant of experience and behavior. American Psychologist, 40, 1189-1202.

Kirsch, I. (1990). Changing expectations: A key to effective psychotherapy. Belmont: Brooks/Cole.

Kirsch, I., Mearns, J., \& Catanzaro, S. J. (1990). Mood-regulation expectancies as determinants of dysphoria in college students. Journal of Counseling Psychology, 37, 306-312.

Klein, K., \& Boals, A. (2001). Expressive writing can increase working memory capacity. Journal of Experimental Psychology: General, 130, $520-533$.

Kleinbaum, D. G., Kupper, L. L., Muller, K. E., \& Nizam, A. (1998). Applied regression analysis and other multivariable methods (3rd ed.). Pacific Grove, CA: Brooks/Cole.

Langens, T. A., \& Schüler, J. (2005). Written emotional expression and emotional well-being: The moderating role of fear of rejection. Personality and Social Psychology Bulletin, 31, 818-830.

Lazarus, R. S., \& Folkman, S. (1984). Stress, appraisal, and coping. New York: Springer.

Lepore, S. J., Ragan, J. D., \& Jones, S. (2000). Talking facilitates cognitive-emotional processes of adaptation to an acute stressor. Journal of Personality and Social Psychology, 78, 499-508.

Lepore, S. J., \& Smyth, J. M. (2002). The writing cure: How expressive writing promotes health and emotional well-being. Washington, DC: American Psychological Association.

Miller, S. M., \& Schnoll, R. A. (2000). When seeing is feeling: A cognitive-emotional approach to coping with health stress. In M. Levis \& J. Havibond-Jones (Eds.), Handbook of emotions (2nd ed., pp. 540570). New York: Guilford Press.

Parkinson, B., \& Totterdell, P. (1999). Classifying affect-regulation strategies. Cognition and Emotion, 13, 277-303.

Parkinson, B., Totterdell, P., Briner, R. B., \& Reynolds, S. (1996). Changing moods: The psychology of mood and mood regulation. London: Addison Wesley.

Pennebaker, J. W. (1997). Opening up: The healing power of expressing emotions (2nd ed.). New York: Guilford Press.

Pennebaker, J. W., \& Beall, S. K. (1986). Confronting a traumatic event: Toward an understanding of inhibition and disease. Journal of Abnormal Psychology, 95, 274-281.

Pennebaker, J. W., Mayne, T., \& Francis, M. (1997). Linguistic predictors of adaptive bereavement. Journal of Personality and Social Psychology, $72,863-871$.

Pennebaker, J. W., \& Seagal, J. D. (1999). Forming a story: The health benefits of narrative. Journal of Clinical Psychology, 55, 1243-1254.

Pennebaker, J. W., \& Watson, D. (1991). The psychology of somatic symptoms. In L. J. Kirmayer \& J. M. Robbins (Eds.), Current concepts of somatization: Research and clinical perspectives (pp. 21-35). Washington, DC: American Psychiatric Association.

Scheier, M. F., \& Carver, C. S. (2003). Self-regulatory processes and responses to health threats: Effects of optimism on well-being. In J. Suls \& K. A. Wallstone (Eds.), Social psychological foundations of health and illness (pp. 395-428). Malden, MA: Blackwell Publishers.

Scheier, M. F., Carver, C. S., \& Bridges, M. W. (2001). Optimism, pessimism, and psychological well-being. In E. C. Chang (Ed.), Optimism and pessimism: Implications for theory, research, and practice (pp. 189-216). Washington, DC: American Psychological Association.

Scheier, M. F., Matthews, K. A., Owens, J. F., Magovern, G. J, Sr., Lefebvre, R. C., Abbott, R. A., \& Carver, C. S. (2003). Dispositional optimism and recovery from coronary artery bypass surgery: The beneficial effects on physical and psychological well-being. In P. Salovey \& A. J. Rothman (Eds.), Social psychology of health (pp. 342-361). New York: Psychology Press. 
Segerstrom, S. C., Taylor, S. E., Kemeny, M. E., \& Fahey, J. L. (1998). Optimism is associated with mood, coping and immune change in response to stress. Journal of Personality and Social Psychology, 74, $1646-1655$.

Smyth, J. M. (1998). Written emotional expression: Effect sizes, outcome types, and moderating variables. Journal of Consulting and Clinical Psychology, 66, 174-184.

Thayer, R. E., Newman, J. R., \& McClain, T. M. (1994). Self-regulation of mood: Strategies for changing a bad mood, raising energy, and reducing tension. Journal of Personality and Social Psychology, 67, 910-925.

Uchino, B. N., Cacioppo, J. T., \& Kiecolt-Glaser, J. K. (1996). The relationship between social support and physiological processes: A review with emphasis on underlying mechanisms and implications for health. Psychological Bulletin, 119, 488-531.

van Gennep, A. (1981). Les rites de passage [Rites of passage]. Paris: Picard.

Weinberger, J., \& Eig, A. (1999). Expectancies: The ignored common factor in psychotherapy. In I. Kirsch (Ed.), How expectancies shape experience (pp. 357-382). Washington, DC: American Psychological Association.

Wortman, C. B., \& Silver, R. C. (1989). The myths of coping with loss. Journal of Consulting and Clinical Psychology, 57, 349-357.

Wortman, C. B., \& Silver, R. C. (2001). The myths of coping with loss revisited. In M. S. Stroebe \& R. O. Hansson (Eds.), Handbook of bereavement research: Consequences, coping, and care (pp. 405-429). Washington, DC: American Psychological Association. 